\title{
A Phase 3, Double-Blind, Randomized, Placebo-Controlled Study of Vilazodone in Adolescents with Major Depressive Disorder
}

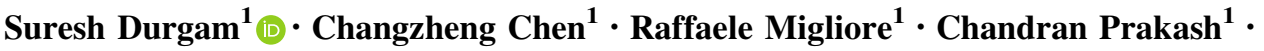 \\ John Edwards ${ }^{1}$ Robert L. Findling ${ }^{2}$
}

Published online: 9 April 2018

(C) The Author(s) 2018

\begin{abstract}
Background Major depressive disorder (MDD) is a serious illness in children and adolescents. Vilazodone is a selective serotonin reuptake inhibitor approved for MDD in adults. This study evaluated the efficacy, safety, and tolerability of vilazodone in adolescent patients, ages 12-17 years, with MDD (NCT01878292).

Methods This double-blind, randomized, placebo-controlled, parallel-group, fixed-dose study was conducted at 56 study centers in the United States and was 10 weeks in duration (a 1-week screening period, an 8-week doubleblind treatment period, and a 1-week double-blind downtaper period). Outpatients with an MDD diagnosis based on Diagnostic and Statistical Manual of Mental Disorders, Fourth Edition, Text Revision criteria were included in the study. Clinical inclusion criteria required a Children's Depression Rating Scale-Revised (CDRS-R) total score of $\geq 40$ and Clinical Global Impressions-Severity (CGI-S) score of $\geq 4$. Patients were randomized 1:1:1 to 8 weeks of double-blind treatment with placebo $(n=174)$, vilazodone $15 \mathrm{mg} /$ day $(n=175)$, or vilazodone $30 \mathrm{mg} /$ day $(n=180)$. The primary and secondary efficacy parameters were change from baseline to week 8 in CDRS-R total score and CGI-S score, respectively. Safety parameters included adverse events (AEs); clinical laboratory, vital sign, and
\end{abstract}

Electronic supplementary material The online version of this article (https://doi.org/10.1007/s40272-018-0290-4) contains supplementary material, which is available to authorized users.

Suresh Durgam

Suresh.Durgam@Allergan.com

Allergan plc, 5 Giralda Farms, Madison, NJ 07940, USA

2 Johns Hopkins University and Kennedy Krieger Institute, Baltimore, Maryland, USA electrocardiogram parameters; and the Columbia-Suicide Severity Rating Scale.

Results Approximately $86 \%$ of patients completed doubleblind treatment. There was no statistically significant difference between vilazodone $15 \mathrm{mg} /$ day or $30 \mathrm{mg} /$ day and placebo in change from baseline in CDRS-R score. Change in CGI-S score was not significant after adjustment for multiple comparisons. The most common treatment-emergent AEs were nausea, upper abdominal pain, vomiting, diarrhea, nasopharyngitis, headache, and dizziness. Reports of suicidal ideation (placebo, 33.3\%; vilazodone 15 $\mathrm{mg} / \mathrm{day}, 36.0 \%$; vilazodone $30 \mathrm{mg} / \mathrm{day}, 31.1 \%$ ) and suicidal behavior (placebo, 1.8\%; vilazodone $15 \mathrm{mg} /$ day, $1.1 \%$; vilazodone $30 \mathrm{mg} /$ day, $1.1 \%$ ) were similar between treatment groups. There were no deaths in the study.

Conclusions The efficacy of vilazodone for the treatment of MDD in adolescent patients could not be confirmed in this study. Vilazodone was generally safe and well tolerated, with treatment-emergent AEs similar to those in adult patients.

Clinical Trial Registration NCT01878292.

\section{Key Points}

In pediatric patients with major depressive disorder, there was no significant difference between vilazodone and placebo in primary or secondary efficacy parameters.

The safety profile of vilazodone in pediatric patients with major depressive disorder was similar to that observed in the adult population. 


\section{Introduction}

Major depressive disorder (MDD) is a common mental health problem in adolescents. For individuals between the ages of 13 and 17 years, lifetime prevalence in the United States is estimated at $12.6 \%$ for a major depressive episode (single or recurrent lifetime) and $10.6 \%$ for MDD [1]. Approximately $40 \%$ of pediatric patients recover without specific treatment during the first depressive episode; however, patients who recover remain at risk for recurrence or dysthymia, while those who do not recover have an increased risk for chronic depression [2]. The presence of depressive symptoms during early adolescence is associated with later depression, anxiety disorders, substance abuse, suicide risk, school failure, recurrent unemployment, and early pregnancy [3]. If left untreated, adolescent depression can affect the development of emotional, cognitive, and social skills; interfere with family relationships; and lead to substantial morbidity and mortality [4].

Evidence-based treatments, which include psychosocial interventions and pharmacotherapy, can improve outcomes in childhood and adolescent depressive disorders. Acute and continuation treatment of depression is recommended for all adolescent patients, with the goal of achieving significant reduction in symptoms and consolidating treatment response to prevent relapse; maintenance treatment may be recommended for patients with severe or chronic depressive conditions to deter recurrence [4]. Supportive treatment approaches (e.g., active listening, problem solving, coping skills) may be sufficient for adolescents with uncomplicated or brief depression; for adolescents who do not respond or who have complicated or severe depression, psychotherapy, such as cognitive behavioral therapy (CBT) or interpersonal psychotherapy (IPT), pharmacotherapy, or a combination of approaches is warranted [4].

Despite the recommendations above, the most effective approach to depression treatment in pediatric patients is uncertain. CBT and IPT are the most widely studied nonpharmacological approaches to depression treatment in adolescents [5]. While both treatments, alone and in combination with antidepressant medication, have demonstrated efficacy in adolescents, findings have been inconsistent [4]. Additionally, several antidepressants have been evaluated for depression treatment in children and adolescents, but only the selective serotonin reuptake inhibitors (SSRIs) fluoxetine (ages 8-18 years) and escitalopram (ages 12-17 years) are approved by the US Food and Drug Administration (FDA) for the treatment of MDD in pediatric patients [6-8]. Given the prevalence of depressive episodes in adolescents and the lack of approved pharmacotherapies, there is an ongoing need for effective treatment in this population [9].
Vilazodone is an SSRI and 5- $\mathrm{HT}_{1 \mathrm{~A}}$ receptor partial agonist that is approved by the FDA for the treatment of MDD in adults [10]. The efficacy and safety of vilazodone in adults was evaluated in four randomized, double-blind, placebo-controlled, 8- to 10-week clinical trials [11-14] and one long-term, 52-week, open-label study [15]. We are presenting results from a phase 3 study conducted to evaluate the efficacy, safety, and tolerability of vilazodone in adolescent outpatients with MDD.

\section{Methods}

The study was conducted in the United States from 2013 to 2016 at 56 study centers in full compliance with the Declaration of Helsinki and International Conference on Harmonisation guidelines for Good Clinical Practice. Each study center was experienced in treating the pediatric population and used available guidelines to minimize patient risk or distress. The investigator at each study center was responsible for study management and ensuring study compliance. The protocol and amendments were approved by an institutional review board at each study center, and all patients (or a parent or legal guardian) provided written informed consent.

\subsection{Study Design and Patient Selection}

This was a 10-week, double-blind, randomized, placebocontrolled, parallel-group, fixed-dose study of vilazodone $15 \mathrm{mg} /$ day or $30 \mathrm{mg} /$ day in adolescent patients with MDD (NCT01878292). The study comprised a 1-week screening period, followed by an 8-week double-blind treatment period, and a 1-week double-blind down-taper period.

Male and female patients aged 12-17 years with a diagnosis of MDD for a minimum of 6 weeks were included in the study; diagnosis was based on Diagnostic and Statistical Manual of Mental Disorders, Fourth Edition, Text Revision (DSM-IV-TR) [16] criteria. To ensure an accurate MDD diagnosis, the Kiddie Schedule for Affective Disorders and Schizophrenia-Present and Lifetime (K-SADS-PL) interview [17], administered by a trained clinician to interview pediatric patients and caregivers, was used to confirm MDD diagnosis. Clinical inclusion criteria required a Children's Depression Rating Scale-Revised (CDRS-R) [18] total score $\geq 40$ and a Clinical Global Impressions-Severity (CGI-S) [19] score $\geq 4$. Patients were required to have a caregiver who was responsible for safety monitoring and could provide information about the patient's condition, oversee administration of study drug, and accompany the patient to all study visits. Psychotherapy or behavior therapy were allowed if either was initiated at least 3 months prior to 
screening and there was no plan to change such therapies during the study.

Key exclusion criteria included a principal DSM-IV-TR Axis I diagnosis other than MDD in the past 3 months or prior diagnosis of mental retardation or other cognitive disorders; comorbid diagnoses of learning disorders, attention deficit disorder with or without hyperactivity, communication disorders, separation anxiety disorder, dysthymic disorder, oppositional defiant disorder, and anxiety disorders were allowed. Patients with nonresponse to adequate treatment (i.e., at least 8 weeks' duration) with two or more SSRIs or serotonin and norepinephrine reuptake inhibitors (SNRIs) or the need for concomitant psychotropic medication were excluded. History of drug or alcohol abuse or dependence within the past year was also exclusionary. Patients were additionally excluded for significant suicide risk judged by the investigator based on the psychiatric interview or information collected from the Columbia-Suicide Severity Rating Scale (C-SSRS) [20], or suicide attempt within the past year. Any unstable medical condition or any condition that could interfere with study conduct, confound interpretation of study results, or endanger patient well-being was an additional reason for exclusion.

\subsection{Randomization, Blinding, and Treatment}

Computerized randomization codes were generated; blinding of patients, investigators, and study site personnel was implemented and maintained by interactive voice/web response systems. Breaking the blind for any reason resulted in discontinuation from the study. Based on modeling and simulation of adult pharmacokinetic (PK) data from vilazodone studies (a dose range of 2.5-80 $\mathrm{mg} /$ day) considering the vilazodone tablet strengths available $(5 \mathrm{mg}, 10 \mathrm{mg}$, and $20 \mathrm{mg}$ ), dosing schemes of 15 $\mathrm{mg} / \mathrm{day}$ and $30 \mathrm{mg} /$ day were selected for this study. Each approach was expected to lead to similar up-titration and steady-state exposures as those observed with $20 \mathrm{mg}$ and $40 \mathrm{mg}$, respectively, in adult patients. Study medication was dispensed as vilazodone 5-, 10-, and 20-mg tablets and matching placebo tablets, identical in appearance and packaging. Eligible patients were randomized $(1: 1: 1)$ to placebo or fixed-dose vilazodone $15 \mathrm{mg} /$ day or $30 \mathrm{mg} /$ day. Patients randomized to vilazodone received $5 \mathrm{mg}$ /day for days $1-3$ and $10 \mathrm{mg} /$ day for days $4-7$. Patients in the vilazodone $15-\mathrm{mg}$ /day group were titrated up to $15 \mathrm{mg}$ /day starting at week 2 ; patients in the vilazodone $30-\mathrm{mg} /$ day group were titrated up to $20 \mathrm{mg} /$ day starting at week 2 and to $30 \mathrm{mg}$ /day starting at week 3 . During the 1 -week doubleblind down-taper period, patients receiving vilazodone $15 \mathrm{mg} /$ day were titrated down to $5 \mathrm{mg} /$ day for 7 days; patients receiving vilazodone $30 \mathrm{mg} / \mathrm{day}$ were titrated down to $15 \mathrm{mg} /$ day for 4 days, then $5 \mathrm{mg} /$ day for 3 days (see the electronic supplementary material, Supplemental Figure 1). Patients randomized to placebo continued taking placebo tablets during the 7-day down-taper period.

\subsection{Efficacy and Safety Parameters}

The prespecified primary efficacy parameter was change from baseline to week 8 in CDRS-R total score [assessed at screening (week -1 ), baseline (week 0 ), and the end of double-blind study weeks 1, 2, 3, 4, 6, and 8]. The prespecified secondary efficacy parameter was change from baseline to week 8 in CGI-S score, assessed at the same study weeks as the primary efficacy parameter. Additional prespecified efficacy parameters were assessed at each post-baseline visit (weeks 1, 2, 3, 4, 6, and 8): CGI-Improvement (CGI-I) [19] score, CDRS-R response ( $\geq 40 \%$ reduction from baseline in CDRS-R total score), and CDRS-R remission (total score $\leq 28$ ). A post hoc analysis was conducted to determine CGI-I response [score of 1 (very much improved) or 2 (much improved)]. Safety was assessed by adverse event (AE) reports, clinical laboratory tests, vital sign measurement, physical examinations, electrocardiogram (ECG) findings, and C-SSRS assessments. PK samples were collected at weeks 3,6 , and 8 (visits 5,7 , and 8).

\subsection{Determination of Sample Size}

Based on a mixed-effect model for repeated measures (MMRM) adjusted for multiple comparisons using the matched parallel gatekeeping procedure, a sample size of 495 patients (165 per treatment group) was planned to provide $85 \%$ power to detect an effect size of 0.36 at a twosided significance level of $0.5 \%$. The simulation assumed a correlation of 0.7 between the repeated measures, and a dropout rate of $17 \%$, based on historical studies in pediatric patients with MDD. Based on a prespecified interim analysis of blinded sample size re-estimation, the sample size was later increased from 495 to 525 patients (175 per group) to maintain the desired $85 \%$ power.

\subsection{Statistical Methods}

Safety analyses were conducted in the safety population, defined as all patients in the randomized population who took at least one dose of double-blind study drug. Efficacy analyses were based on the intent-to-treat (ITT) population (all patients in the safety population who had a baseline and one or more post-baseline CDRS-R total score assessment).

The primary efficacy analysis, change from baseline to week 8 in CDRS-R total score, was performed using MMRM with treatment group, study center, visit, and 
treatment group-by-visit interaction as the fixed effects and the baseline value and baseline value-by-visit interaction as the covariates. An unstructured covariance matrix was used to model the covariance of within-patient scores. The Kenward-Roger approximation [21] was used to estimate denominator degrees of freedom. The analysis was based on all post-baseline scores using the observed cases (OC) approach without imputation of missing values.

The secondary efficacy parameter, change from baseline in CGI-S score at week 8, was analyzed using an MMRM approach that was similar to the one used for the primary efficacy parameter. To control the overall type I error rate for multiple comparisons across the primary and the secondary efficacy parameters, the matched parallel gatekeeping procedure [22] was implemented; statistically significant changes from baseline in CGI-S score could therefore only be claimed if differences in the primary outcome were statistically significant in favor of vilazodone. CGI-I score was analyzed using an MMRM approach with the baseline CGI-S score as a covariate. CDRS-R response and remission rates were analyzed using a generalized linear mixed model with random intercept and fixed terms of treatment group, visit, treatment-by-visit interaction, and baseline score. CGI-I response was analyzed post hoc using a last observation carried forward approach. All statistical tests for efficacy analyses were two-sided hypothesis tests performed at the 5\% level of significance; confidence intervals (CIs) were two-sided 95\% CIs, unless stated otherwise. All safety parameters were analyzed descriptively.

\section{Results}

\subsection{Patients}

A total of 529 patients were randomized to placebo, vilazodone $15 \mathrm{mg} / \mathrm{day}$, or vilazodone $30 \mathrm{mg} / \mathrm{day}$ (Figure 1). Of the 526 patients in the safety population, 452 $(85.9 \%)$ completed double-blind treatment (placebo $=$ $83.0 \%$; vilazodone $15 \mathrm{mg}=85.1 \%$; vilazodone $30 \mathrm{mg}=$ $89.4 \%$ ). The most common reasons for premature discontinuation in the overall study population were withdrawal of consent (4.6\%) and AEs $(4.0 \%)$; discontinuation due to AEs was higher in patients treated with vilazodone $(15 \mathrm{mg} /$ day $=5.1 \% ; 30 \mathrm{mg} /$ day $=4.4 \%)$ than in patients treated with placebo $(2.3 \%)$.

Baseline characteristics were similar across treatment groups (Table 1). Mean patient age was approximately 15 years, with a higher percentage of female patients than male patients in each treatment group. Baseline CDRS-R total scores and CGI-S scores indicated similar levels of disease severity across treatment groups, with a CDRS-R total score of $\geq 40$ being indicative of depression in adolescents [23].

\subsection{Efficacy Outcomes}

Mean CDRS-R total scores decreased from baseline to week 8 in all treatment groups, indicating improvement in depressive symptoms; however, the least squares mean difference (LSMD) was not statistically significant for either vilazodone group versus the placebo group (Figure 2, Table 2). After adjustment for multiple comparisons, there was no significant difference between either vilazodone group and placebo in change from baseline to week 8 in CGI-S score (Table 2). There were also no other significant differences in any additional outcome.

\subsection{Safety Outcomes}

\subsubsection{Extent of Exposure}

The mean (standard deviation) treatment duration was 51.2 (14.0) days for placebo-treated patients and 51.7 (12.3) days and 53.1 (10.6) days for vilazodone $15 \mathrm{mg} /$ day- and $30 \mathrm{mg} /$ day-treated patients, respectively. Median (min, max) treatment duration was $56(4,69)$ days for both placebo- and vilazodone $15 \mathrm{mg} /$ day-treated patients, and $56(7,70)$ for vilazodone $30 \mathrm{mg} /$ day-treated patients. An interim population PK analysis found the $15-\mathrm{mg}$ and $30-\mathrm{mg}$ doses in adolescents achieved exposures similar to 20-mg and 40-mg doses, respectively, in adult patients [24].

\subsubsection{Adverse Events}

The percentage of patients with one or more treatmentemergent AE (TEAE) was higher in vilazodone-treated patients than in placebo-treated patients (Table 3). TEAEs that occurred in $\geq 5 \%$ in either vilazodone treatment group at a rate twice that of placebo were nausea, upper abdominal pain, vomiting, and dizziness. Serious AEs (SAEs) occurred in six patients, including one patient in the placebo group (suicidal ideation), two patients in the vilazodone 15-mg/day group (alanine aminotransferase increased and mental status changes), and three patients in the vilazodone 30-mg/day group (intentional overdose with marketed buspirone and suicide attempt in one patient, pilonidal cyst in one patient, and suicidal ideation in one patient). Each patient with a suicide-related SAE discontinued from the study and recovered. Two patients had suicide-related SAEs that were considered related to treatment [suicidal ideation (placebo) and intentional overdose/suicide attempt (vilazodone $30 \mathrm{mg} /$ day)]. TEAEs that led to discontinuation in more than one patient included nausea (vilazodone, $n=3$; placebo, $n=0$ ), nightmares 


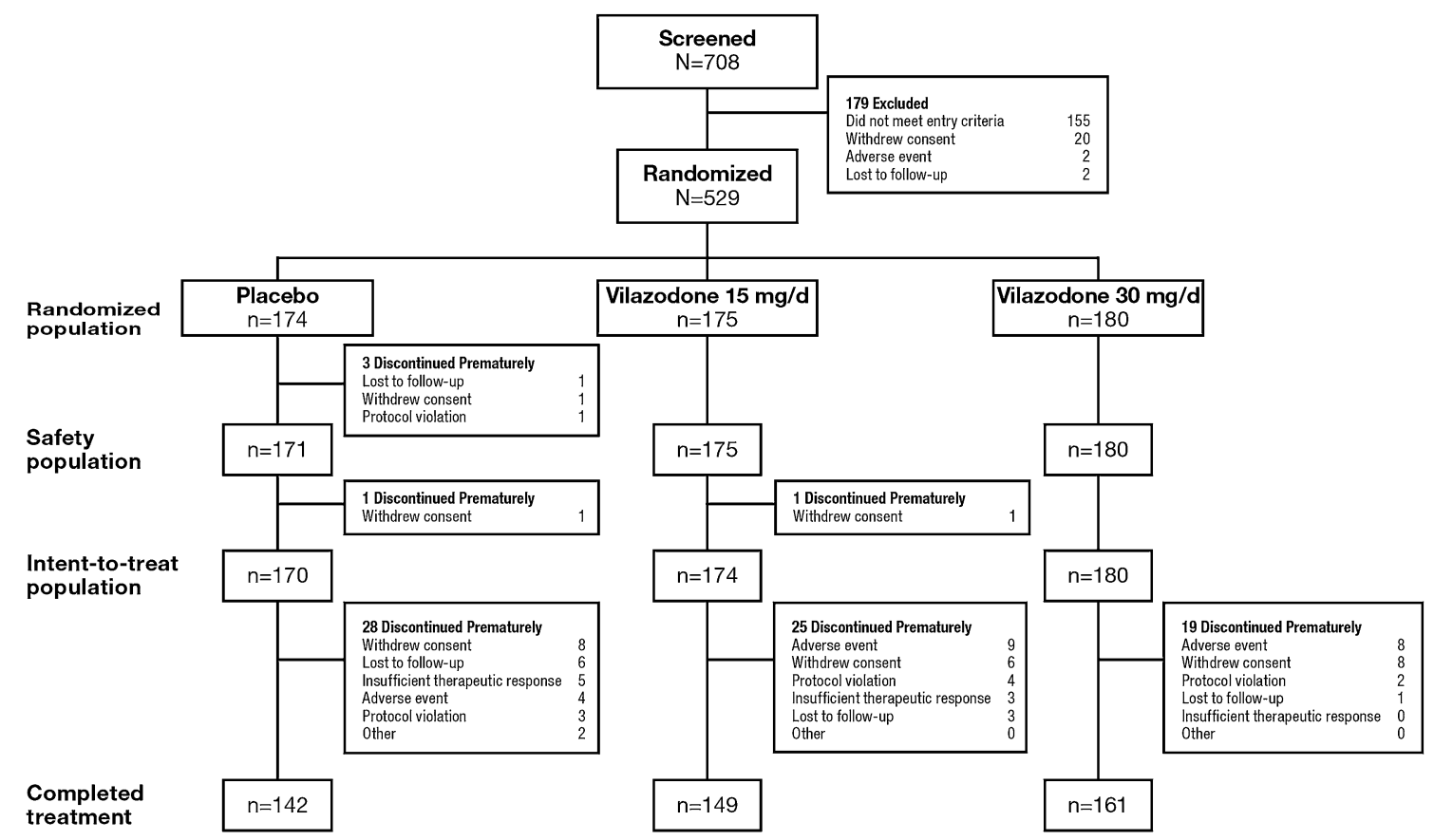

Fig. 1 Patient disposition

Table 1 Demographic and baseline characteristics

\begin{tabular}{lccc}
\hline Demographic characteristics (safety population) & $\begin{array}{l}\text { Placebo } \\
(n=171)\end{array}$ & $\begin{array}{c}\text { Vilazodone } \\
15 \mathrm{mg} / \mathrm{day} \\
(n=175)\end{array}$ & $\begin{array}{c}\text { Vilazodone } \\
30 \mathrm{mg} / \mathrm{day} \\
(n=180)\end{array}$ \\
\hline Age, mean (SD), years & $14.9(1.7)$ & $14.9(1.6)$ & $14.6(1.6)$ \\
Sex, $n$ (\%) & & & \\
Male & $68(39.8)$ & $72(41.1)$ & $73(40.6)$ \\
Female & $103(60.2)$ & $103(58.9)$ & $107(59.4)$ \\
Race, $n$ (\%) & & & \\
White & $110(64.3)$ & $115(65.7)$ & $121(67.2)$ \\
Black or African-American & $45(26.3)$ & $48(27.4)$ & $49(27.2)$ \\
Asian & $6(3.5)$ & $3(1.7)$ & 0 \\
American Indian or Alaska Native & $2(1.2)$ & $2(1.1)$ & $4(2.2)$ \\
Other & $8(4.7)$ & $7(4.0)$ & $6(3.3)$ \\
Weight, mean (SD), kg & $71.9(20.8)$ & $70.1(20.7)$ & $70.9(20.6)$ \\
Height, mean (SD), cm & $166.1(8.9)$ & $166.2(9.3)$ & $165.7(9.1)$ \\
BMI, mean (SD), kg/m ${ }^{2}$ & $26.0(7.2)$ & $25.3(6.9)$ & $25.7(6.7)$ \\
Duration of MDD, mean (SD), years & $2.4(2.3)$ & $2.6(2.3)$ & $2.4(2.1)$ \\
Duration of current episode, mean (SD), months & $11.0(12.0)$ & $12.0(14.2)$ & $12.6(14.7)$ \\
Age at onset, mean (SD), years & $12.5(2.5)$ & $12.3(2.7)$ & $12.3(2.6)$ \\
Baseline efficacy scores (ITT population) & & & $56.8(8.5)$ \\
CDRS-R total score, mean (SD) & $57.5(8.6)$ & $57.8(8.7)$ & $4.6(0.6)$ \\
CGI-S score, mean (SD) & $4.5(0.6)$ & $4.6(0.6)$ & \\
\hline
\end{tabular}

$B M I$ body mass index, CDRS-R Children's Depression Rating Scale-Revised, CGI-S Clinical Global Impressions-Severity, $I T T$ intent-to-treat, $M D D$ major depressive disorder, $S D$ standard deviation 
Fig. 2 Change from baseline in CDRS-R total score (ITT Population, MMRM). CDRS-R Children's Depression Rating Scale-Revised, ITT intent-totreat, $L S$ least squares, MMRM mixed-effect model for repeated measures

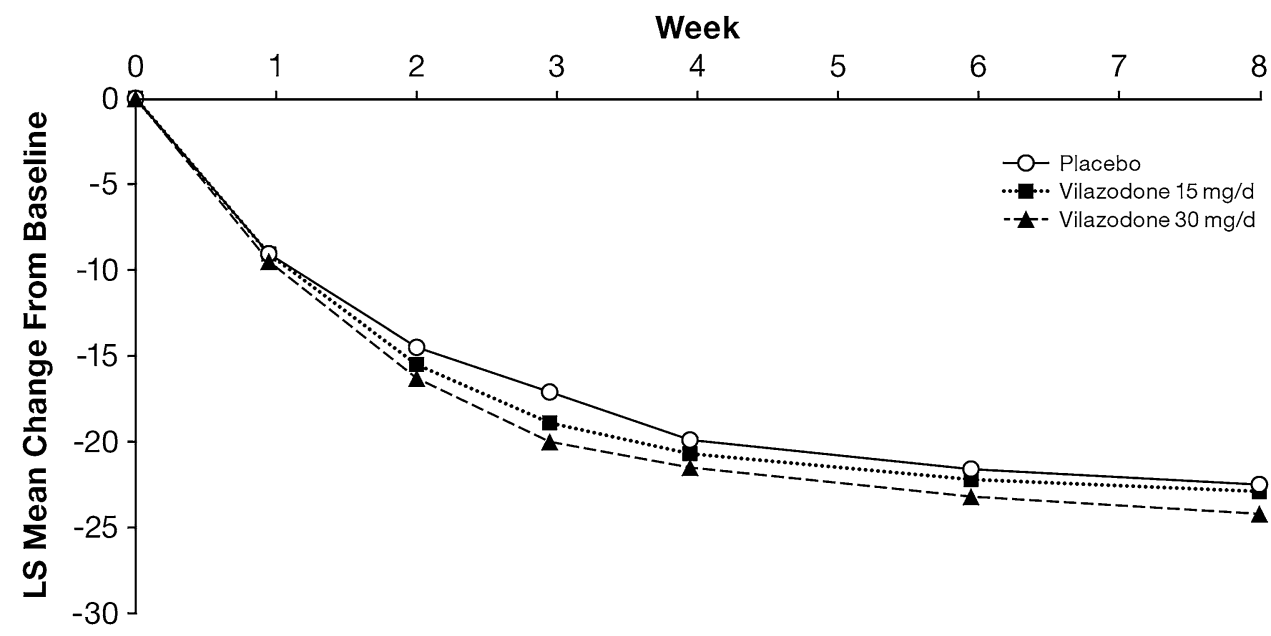

(vilazodone, $n=2$; placebo, $n=0$ ), suicidal ideation (vilazodone, $n=4$; placebo, $n=1$ ), and depression (vilazodone, $n=4$; placebo, $n=0$ ) (Table 4).

\subsubsection{Laboratory Tests, Vital Signs, and Electrocardiograms}

Mean changes from baseline in clinical laboratory parameters and vital signs were generally small and similar among treatment groups. Overall, the incidence of postbaseline potentially clinically significant laboratory values was low and similar in the three treatment groups; no patient met Hy's law criteria [alanine aminotransferase or aspartate aminotransferase elevation $\geq 3$ times the upper limit of normal (ULN), total bilirubin elevation $>2$ times ULN, and alkaline phosphatase $<2$ times ULN]. No patient had a QTc of $>500 \mathrm{~ms}$ or a clinically significant ECG; no new safety concerns were identified.

\subsubsection{Suicidal Ideation and Behavior}

There were no completed suicides. Based on C-SSRS findings, the incidences of suicidal ideation (placebo, $33.3 \%$; vilazodone $15 \mathrm{mg} /$ day, $36.0 \%$; vilazodone 30 $\mathrm{mg} / \mathrm{day}, 31.1 \%$ ) and suicidal behavior (placebo, $1.8 \%$; vilazodone $15 \mathrm{mg} /$ day and $30 \mathrm{mg} /$ day, $1.1 \%$ ) were similar between treatment groups, although nonspecific active suicidal thoughts were more frequent in the vilazodone $15-\mathrm{mg}$ /day group. Four patients recorded 'yes' to suicide attempt on the C-SSRS (placebo, $n=2$; vilazodone 15 $\mathrm{mg} /$ day and $30 \mathrm{mg} /$ day, $n=1 \mathrm{each}$ ).

\section{Discussion}

In this randomized, placebo-controlled, double-blind study in adolescent patients with MDD, CDRS-R total score improved from baseline in each treatment group, but the LSMD at week 8 was not statistically significant for either vilazodone $15 \mathrm{mg} /$ day or $30 \mathrm{mg} /$ day versus placebo. Additionally, no significant differences were observed for vilazodone versus placebo in mean change from baseline in CGI-S score when $P$ values were adjusted for multiple comparisons. Vilazodone was generally well tolerated, and TEAEs in adolescent patients were similar to what has been observed in adult patients [11-15]. Examining these negative results in the context of other randomized placebo-controlled trials of antidepressants for the treatment of adolescent depression may help explain our findings and expand the base of knowledge pertaining to vilazodone.

Although the optimal treatment for adolescent depression is unclear, clinical guidelines recommend the use of psychosocial interventions, SSRIs, or combined treatment $[4,25]$. However, in clinical trials of antidepressants in pediatric and adolescent patients with MDD, evidence of efficacy is inconsistent, with long-term effectiveness and relapse prevention data lacking in this population [5]. Several antidepressant agents have encountered difficulties demonstrating a treatment effect versus placebo, with high placebo response rates (up to 60\%) contributing to the problem [26]. Likewise, in our study, improvements in mean change from baseline in CDRS-R total score were large in the placebo group (-22.5), which may have played a role in our inability to detect treatment differences in either vilazodone group (15 mg/day, $-22.9 ; 30 \mathrm{mg} /$ day, -24.2). Moreover, over $50 \%$ of patients in the placebo group were rated as very much or much improved (CGI-I response of 1 or 2), supporting a high placebo effect in this treatment group. Additional methodological issues, including study site differences, patient age, inclusion/ 
Table 2 Prespecified and post hoc efficacy outcomes at week 8 (ITT population, MMRM)

\begin{tabular}{|c|c|c|c|}
\hline & $\begin{array}{l}\text { Placebo } \\
(n=170)\end{array}$ & $\begin{array}{l}\text { Vilazodone } \\
15 \mathrm{mg} / \text { day } \\
(n=174)\end{array}$ & $\begin{array}{l}\text { Vilazodone } \\
30 \mathrm{mg} / \mathrm{day} \\
(n=180)\end{array}$ \\
\hline \multicolumn{4}{|l|}{ CDRS-R total score } \\
\hline Week 8 score $(\mathrm{SD})$ & $34.0(12.9)$ & $33.8(12.0)$ & $32.5(11.5)$ \\
\hline LS mean change from baseline (SE) & $-22.5(0.9)$ & $-22.9(0.9)$ & $-24.2(0.9)$ \\
\hline LSMD vs placebo $(95 \% \mathrm{CI})$ & - & $-0.5(-3.0$ to 2.0$)$ & $-1.7(-4.2$ to 0.7$)$ \\
\hline Adjusted $P$ value ${ }^{\mathrm{a}}$ & - & 0.7162 & 0.3267 \\
\hline$P$ value & - & 0.7162 & 0.1634 \\
\hline \multicolumn{4}{|l|}{ CGI-S total score } \\
\hline Week 8 score $(\mathrm{SD})$ & $2.9(1.2)$ & $2.7(1.2)$ & $2.7(1.1)$ \\
\hline LS mean change from baseline (SE) & $-1.6(0.1)$ & $-1.8(0.1)$ & $-1.9(0.1)$ \\
\hline LSMD vs placebo $(95 \% \mathrm{CI})$ & - & $-0.2(-0.5$ to 0.0$)$ & $-0.3(-0.5$ to 0.0$)$ \\
\hline Adjusted $P$ value ${ }^{\mathrm{a}}$ & - & 0.7162 & 0.3267 \\
\hline$P$ value & - & 0.0852 & 0.0323 \\
\hline \multicolumn{4}{|l|}{ CGI-I total score } \\
\hline Week 8 score $(\mathrm{SD})$ & $2.4(1.1)$ & $2.2(1.2)$ & $2.2(1.0)$ \\
\hline LS mean score at week 8 (SE) & $2.4(0.1)$ & $2.3(0.1)$ & $2.2(0.1)$ \\
\hline LSMD vs placebo (95\% CI) & - & $-0.1(-0.4$ to 0.1$)$ & $-0.2(-0.5$ to 0.0$)$ \\
\hline$P$ value & - & 0.3072 & 0.0563 \\
\hline \multicolumn{4}{|l|}{ CDRS-R response ${ }^{b}$} \\
\hline Responders, $n(\%)^{\mathrm{c}}$ & $80(55.9)$ & $83(56.1)$ & $103(63.2)$ \\
\hline Odds ratio $(95 \% \mathrm{CI})$ & - & $1.0(0.5-2.1)$ & $1.6(0.8-3.2)$ \\
\hline$P$ value & - & 0.9907 & 0.2115 \\
\hline \multicolumn{4}{|l|}{ CDRS-R remission $^{\mathrm{d}}$} \\
\hline Remitters, $n(\%)^{\mathrm{c}}$ & $63(44.1)$ & $62(41.9)$ & $72(44.2)$ \\
\hline Odds ratio $(95 \% \mathrm{CI})$ & - & $1.0(0.5-2.0)$ & $1.1(0.5-2.2)$ \\
\hline$P$ value & - & 0.9477 & 0.8232 \\
\hline \multicolumn{4}{|l|}{ CGI-I response, score of 1 or 2} \\
\hline Responders, $n(\%)^{\mathrm{e}}$ & $92(54.1)$ & $98(56.3)$ & $112(62.2)$ \\
\hline Odds ratio $(95 \% \mathrm{CI})$ & - & $1.1(0.7-1.7)$ & $1.4(0.9-2.1)$ \\
\hline$P$ value & - & 0.6811 & 0.1248 \\
\hline \multicolumn{4}{|l|}{ CGI-I response, score of 1} \\
\hline Responders, $n(\%)^{\mathrm{e}}$ & $34(20.0)$ & $52(29.9)$ & $52(28.9)$ \\
\hline Odds ratio $(95 \% \mathrm{CI})$ & - & $1.7(1.0-2.8)$ & $1.6(1.0-2.7)$ \\
\hline$P$ value & - & 0.0353 & 0.0547 \\
\hline
\end{tabular}

CDRS-R Children's Depression Rating Scale-Revised, CGI-I Clinical Global Impressions-Improvement, CGI-S CGI-Severity, CI confidence interval, ITT intent-to-treat, $L S$ least squares, LSMD LS mean difference, $M M R M$ mixed-effect model for repeated measures, $S D$ standard deviation, $S E$ standard error

${ }^{a}$ Adjusted $P$ values were obtained from the matched parallel gatekeeping procedure

${ }^{\mathrm{b}}$ CDRS-R response defined as $\geq 40 \%$ total score improvement from baseline at week 8

${ }^{\mathrm{c}}$ Analyzed using a generalized linear mixed model; percentages based on the number of patients available for analysis at week 8 in the ITT population (placebo, $n=143$; vilazodone $15 \mathrm{mg} / \mathrm{day}, n=148$; vilazodone $30 \mathrm{mg} /$ day, $n=163$ )

${ }^{\mathrm{d}}$ CDRS-R remission defined as total score $\leq 28$ at week 8

${ }^{\mathrm{e}} \mathrm{CGI}-\mathrm{I}$ response at week 8 was analyzed using a last observation carried forward approach 
Table 3 Adverse events during the double-blind treatment period (safety population)

\begin{tabular}{|c|c|c|c|}
\hline & $\begin{array}{l}\text { Placebo } \\
(n=171) \\
n(\%)\end{array}$ & $\begin{array}{l}\text { Vilazodone } \\
15 \mathrm{mg} / \text { day } \\
(n=175) \\
n(\%)\end{array}$ & $\begin{array}{l}\text { Vilazodone } \\
30 \mathrm{mg} / \mathrm{day} \\
(n=180) \\
n(\%)\end{array}$ \\
\hline Deaths & 0 & 0 & 0 \\
\hline Any TEAE & $105(61.4)$ & $122(69.7)$ & $135(75.0)$ \\
\hline Any SAE & $1(0.6)$ & $2(1.1)$ & $3(1.7)$ \\
\hline Discontinuations due to AEs & $4(2.3)$ & $9(5.1)$ & $8(4.4)$ \\
\hline \multicolumn{4}{|c|}{ Common TEAEs ( $\geq 2 \%$ of patients in both vilazodone groups) } \\
\hline Nausea $^{\mathrm{a}}$ & $14(8.2)$ & $51(29.1)$ & $49(27.2)$ \\
\hline Headache & $27(15.8)$ & $22(12.6)$ & $29(16.1)$ \\
\hline Upper abdominal pain ${ }^{\mathrm{a}}$ & $11(6.4)$ & $7(4.0)$ & $28(15.6)$ \\
\hline Vomiting $^{\mathrm{a}}$ & $6(3.5)$ & $11(6.3)$ & $21(11.7)$ \\
\hline Diarrhea & $8(4.7)$ & $15(8.6)$ & $16(8.9)$ \\
\hline Dizziness $^{\mathrm{a}}$ & $5(2.9)$ & $8(4.6)$ & $13(7.2)$ \\
\hline Nasopharyngitis & $6(3.5)$ & $6(3.4)$ & $11(6.1)$ \\
\hline Abdominal discomfort & $2(1.2)$ & $7(4.0)$ & $8(4.4)$ \\
\hline Upper respiratory tract infection & $4(2.3)$ & $7(4.0)$ & $7(3.9)$ \\
\hline Insomnia & $5(2.9)$ & $5(2.9)$ & $7(3.9)$ \\
\hline Fatigue & $7(4.1)$ & $4(2.3)$ & $7(3.9)$ \\
\hline Decreased appetite & $1(0.6)$ & $7(4.0)$ & $6(3.3)$ \\
\hline Somnolence & $1(0.6)$ & $8(4.6)$ & $4(2.2)$ \\
\hline
\end{tabular}

$A E$ adverse event, $S A E$ serious $\mathrm{AE}, T E A E$ treatment-emergent $\mathrm{AE}$

${ }^{\mathrm{a}}$ Occured in $\geq 5 \%$ of patients in either vilazodone group at a rate twice that of placebo
Table 4 Treatment-emergent adverse events that led to discontinuation (safety population)

\begin{tabular}{llll}
\hline TEAE & $\begin{array}{l}\text { Placebo } \\
(n=171) \\
n(\%)\end{array}$ & $\begin{array}{l}\text { Vilazodone } \\
15 \mathrm{mg} / \mathrm{day} \\
(n=175) \\
n(\%)\end{array}$ & $\begin{array}{l}\text { Vilazodone } \\
30 \mathrm{mg} / \mathrm{day} \\
(n=180) \\
n(\%)\end{array}$ \\
\hline Nausea & 0 & 0 & $3(1.7)$ \\
Nightmare & 0 & 0 & $2(1.1)$ \\
Suicidal ideation & $1(0.6)$ & $2(1.1)$ & $2(1.1)$ \\
Depression & 0 & $3(1.7)$ & $1(0.6)$ \\
Diarrhea & 0 & 0 & $1(0.6)$ \\
Intentional overdose & 0 & 0 & $1(0.6)$ \\
Muscle twitching & 0 & 0 & $1(0.6)$ \\
Suicide attempt & 0 & 0 & $1(0.6)$ \\
Abdominal discomfort & 0 & $1(0.6)$ & 0 \\
Anxiety & 0 & $1(0.6)$ & 0 \\
Depressive symptom & $1(0.6)$ & 0 & 0 \\
Headache & $1(0.6)$ & 0 & 0 \\
Impulsive behavior & $1(0.6)$ & 0 & 0 \\
Insomnia & 0 & $1(0.6)$ & 0 \\
Irritability & 0 & $1(0.6)$ & 0 \\
Mental status change & 0 & $1(0.6)$ & 0 \\
\hline
\end{tabular}

TEAE treatment-emergent adverse event exclusion criteria, study duration, and outcome measures, have further confounded efficacy outcomes in this therapeutic area [27].

Despite limitations in the evidence, use of antidepressants in pediatric patients has increased in recent years [28]. In a meta-analysis of antidepressants in children and adolescents aged 9-18 years, only fluoxetine was found to be significantly more effective than placebo [9]. Consistent effectiveness data for SSRIs other than fluoxetine is scarce [29-31]; citalopram [32], escitalopram [33], sertraline [34], and paroxetine [35] have reported potential for benefit in a limited number of clinical trials. Evidence for SNRIs in child and adolescent depression is lacking, with some differences for venlafaxine versus placebo reported in two trials [36] and two failed trials reported for duloxetine [37, 38]. Additionally, tricyclic antidepressants have not proven to be more effective than placebo in treating depression in children and adolescents [39]; they are also associated with more adverse effects than SSRIs or SNRIs and can be fatal in overdose.

Nonpharmacological intervention is considered a firstline treatment for adolescent depression, with 15-30\% response reported for brief psychosocial treatment and evidence suggesting that adolescents with moderate depression may benefit from CBT or IPT [4, 40]. Two 
meta-analyses have reported efficacy for CBT, with effect sizes on the lower end of moderate (0.34) [41, 42]. Benefits for IPT have also been reported in randomized clinical trials of adolescents with depression [43, 44], including in one study conducted in a school setting [45]. Studies evaluating combined pharmacotherapy and CBT have mixed results, and further research is warranted to evaluate under what circumstances adding nonpharmacological therapy to pharmacological treatment is beneficial [31, 46, 47].

Although the safety and tolerability of pharmacological treatment are always a primary concern, lack of clear efficacy evidence for some antidepressants in adolescent patients creates an even greater imperative to assess benefits versus harms. Although adverse effects are commonly reported in both active- and placebo-treated patients in adolescent antidepressant studies, reported events are generally similar to those reported in adult trials, and few AEs occur more frequently in children and adolescents than in adults [27]. In our vilazodone study, gastrointestinal events and headache were the most commonly reported TEAEs in vilazodone- and placebo-treated patients. Rates of discontinuation due to AEs, which is a good measure of general tolerability, were relatively low in patients treated with vilazodone $(15 \mathrm{mg} / \mathrm{day}=5.1 \% ; 30 \mathrm{mg} / \mathrm{day}=4.4 \%)$, although they were higher than in placebo-treated patients $(2.3 \%)$.

The most troubling safety issue concerning adolescent patients with depression is the reported link between suicidality and antidepressants in young patients [48, 49]. Since any prospect of potential suicidality is a grave concern, the risk of harm and the potential benefits of treatment must be carefully factored into an informed decision regarding how to treat adolescents with antidepressants [27]. Of note in our study, results of the C-SSRS indicate incidences of suicidal ideation and behavior were similar overall among each treatment group.

Limitations of our study include the lack of an active control, the short duration of treatment, and strict inclusion and exclusion criteria that may limit the generalizability of the results. High placebo response may have limited the ability to detect a statistical difference between the vilazodone- and placebo-treatment groups; however, the mean decrease in CDRS-R scores suggests that individual treatment effect likely occurred for some patients. Additional methodological factors (e.g., number of study sites, inclusion/exclusion criteria, study site differences) may have further affected the results of our study.

\section{Conclusions}

In this double-blind randomized clinical trial of adolescents with MDD, no significant differences between vilazodone and placebo were observed on the primary efficacy parameter; high placebo response may have contributed to an inability to detect a treatment effect. Vilazodone was generally safe and well tolerated, with adverse effects similar to what has been observed in trials of adult patients [11-14]. Clinical trial evidence for pharmacological treatment options in moderate to severe adolescent depression is not robust, with only a few agents (i.e., fluoxetine and escitalopram) reporting positive results [6-8]. Effective treatment options for adolescents with depression are an unmet medical need.

Acknowledgements At the authors' direction, Mildred Bahn, MA, and Carol Brown, MS, of Prescott Medical Communications Group (Chicago, IL), with support from Allergan, assisted in developing the first draft of the manuscript. Additional editorial support, such as editing and formatting, was also provided.

\section{Compliance with Ethical Standards}

Funding The analyses and studies presented in this report were sponsored by Forest Research Institute, an Allergan affiliate. The sponsor was involved in conducting the analyses, interpreting the results, and the decision to submit this manuscript for publication.

Conflict of interest R. Findling receives or has received research support, has acted as a consultant and/or served on a speaker's bureau for Aevi, Akili, Alcobra, Amerex, American Academy of Child \& Adolescent Psychiatry, American Psychiatric Press, Bracket, Epharma Solutions, Forest, Genentech, Guilford Press, Ironshore, Johns Hopkins University Press, KemPharm, Lundbeck, Merck, NIH, Neurim, Nuvelution, Otsuka, PCORI, Pfizer, Physicians Postgraduate Press, Purdue, Roche, Sage, Shire, Sunovion, Supernus Pharmaceuticals, Syneurx, Teva, Tris, TouchPoint, Validus, and WebMD. S. Durgam, C. Chen, R. Migliore, C. Prakash, and J. Edwards are fulltime employees of Allergan.

Ethical approval The study was approved by an institutional review board at each study center involved in the study $(n=56)$ and conducted in compliance with the Declaration of Helsinki and $\mathrm{ICH}$ Guidances on General Considerations for Clinical Trials and Good Clinical Practice.

Informed consent Informed consent was obtained from all individual participants included in the study. Written permission was obtained from parents or legal guardians in accordance with appropriate local laws, where applicable.

Open Access This article is distributed under the terms of the Creative Commons Attribution-NonCommercial 4.0 International License (http://creativecommons.org/licenses/by-nc/4.0/), which permits any noncommercial use, distribution, and reproduction in any medium, provided you give appropriate credit to the original author(s) and the source, provide a link to the Creative Commons license, and indicate if changes were made. 


\section{References}

1. Kessler RC, Petukhova M, Sampson NA, Zaslavsky AM, Wittchen HU. Twelve-month and lifetime prevalence and lifetime morbid risk of anxiety and mood disorders in the United States. Int J Methods Psychiatr Res. 2012;21:169-84.

2. Zalsman G, Brent DA, Weersing VR. Depressive disorders in childhood and adolescence: an overview: epidemiology, clinical manifestation and risk factors. Child Adolesc Psychiatr Clin N Am. 2006;15:827-41 (vii).

3. Fergusson DM, Woodward LJ. Mental health, educational, and social role outcomes of adolescents with depression. Arch Gen Psychiatry. 2002;59:225-31.

4. Birmaher B, Brent D, Issues AWGOQ, Bernet W, Bukstein O, Walter $\mathrm{H}$, et al. Practice parameter for the assessment and treatment of children and adolescents with depressive disorders. J Am Acad Child Adolesc Psychiatry. 2007;46:1503-26.

5. Thapar A, Collishaw S, Pine DS, Thapar AK. Depression in adolescence. Lancet. 2012;379:1056-67.

6. Forest Pharmaceuticals. Prescribing information of Lexapro. 2014. http://pi.actavis.com/data_stream.asp?product_group= 1907\&p=pi\&language=E. Accessed 20 Jan 2017.

7. Eli Lilly and Company. Prescribing information of Prozac. 2016. http://pi.lilly.com/us/prozac.pdf. Accessed 20 Jan 2017.

8. Locher C, Koechlin H, Zion SR, Werner C, Pine DS, Kirsch I, et al. Efficacy and safety of selective serotonin reuptake inhibitors, serotonin-norepinephrine reuptake inhibitors, and placebo for common psychiatric disorders among children and adolescents: a systematic review and meta-analysis. JAMA Psychiatry. 2017;74:1011-20.

9. Cipriani A, Zhou X, Del Giovane C, Hetrick SE, Qin B, Whittington $\mathrm{C}$, et al. Comparative efficacy and tolerability of antidepressants for major depressive disorder in children and adolescents: a network meta-analysis. Lancet. 2016;388:881-90.

10. Allergan. Prescribing information of Viibryd. 2017. http://www. allergan.com/assets/pdf/viibryd_pi. Accessed 27 Mar 2018.

11. Rickels K, Athanasiou M, Robinson DS, Gibertini M, Whalen H, Reed CR. Evidence for efficacy and tolerability of vilazodone in the treatment of major depressive disorder: a randomized, doubleblind, placebo-controlled trial. J Clin Psychiatry. 2009;70:326-33.

12. Khan A, Cutler AJ, Kajdasz DK, Gallipoli S, Athanasiou M, Robinson DS, et al. A randomized, double-blind, placebo-controlled, 8-week study of vilazodone, a serotonergic agent for the treatment of major depressive disorder. J Clin Psychiatry. 2011;72:441-7.

13. Croft HA, Pomara N, Gommoll C, Chen D, Nunez R, Mathews M. Efficacy and safety of vilazodone in major depressive disorder: a randomized, double-blind, placebo-controlled trial. J Clin Psychiatry. 2014;75:e1291-8.

14. Mathews M, Gommoll C, Chen D, Nunez R, Khan A. Efficacy and safety of vilazodone 20 and $40 \mathrm{mg}$ in major depressive disorder: a randomized, double-blind, placebo-controlled trial. Int Clin Psychopharmacol. 2015;30:67-74.

15. Robinson DS, Kajdasz DK, Gallipoli S, Whalen H, Wamil A, Reed CR. A 1-year, open-label study assessing the safety and tolerability of vilazodone in patients with major depressive disorder. J Clin Psychopharmacol. 2011;31:643-6.

16. American Psychiatric Association. Diagnostic and statistical manual of mental disorders, 4th ed., text rev. Washington, DC: American Psychiatric Association. 2000.

17. Kaufman J, Birmaher B, Brent D, Rao U, Flynn C, Moreci P, et al. Schedule for Affective Disorders and Schizophrenia for School-Age Children-Present and Lifetime Version (K-SADS-
PL): initial reliability and validity data. J Am Acad Child Adolesc Psychiatry. 1997;36:980-8.

18. Poznanski EO, Mokros HB. Children's Depression Rating Scale Revised (CDRS R). Los Angeles: Western Psychological Services; 1996.

19. Guy W. ECDEU Assessment Manual for Psychopharmacology. Revised. DHEW publication, no. (ADM) 76-338. Rockville, MD: US Dept of Health, Education, and Welfare, Public Health Service, Alcohol, Drug Abuse, and Mental Health Administration, National Institute of Mental Health, Psychopharmacology Research Branch, Division of Extramural Research Programs; 1976. p. 218-22, 534-7. 1976.

20. Posner K, Brown GK, Stanley B, Brent DA, Yershova KV, Oquendo MA, et al. The Columbia-Suicide Severity Rating Scale: initial validity and internal consistency findings from three multisite studies with adolescents and adults. Am J Psychiatry. 2011;168:1266-77.

21. Kenward MG, Roger JH. Small sample inference for fixed effects from restricted maximum likelihood. Biometrics. 1997;53:983-97.

22. Chen X, Luo X, Capizzi T. The application of enhanced parallel gatekeeping strategies. Stat Med. 2005;24:1385-97.

23. Mayes TL, Bernstein IH, Haley CL, Kennard BD, Emslie GJ. Psychometric properties of the Children's Depression Rating Scale-Revised in adolescents. J Child Adolesc Psychopharmacol. 2010;20:513-6.

24. Khariton T, Jonsson EN, Bergstrand M, Carrothers TJ, Ghahramani P. Population pharmacokinetic (PPK) modeling of vilazodone in adolescent patients with major depressive disorder (MDD). Poster presented at: American Conference of Pharmacometrics; October 2015; Arlington, VA.

25. National Institute for Health and Clinical Excellence (NICE). Depression in children and young people: identification and management (update March 2015); 2005. http://www.nice.org. uk/guidance/index.jsp?action=byID\&o=10970. Accessed 26 May 2017.

26. Bridge JA, Birmaher B, Iyengar S, Barbe RP, Brent DA. Placebo response in randomized controlled trials of antidepressants for pediatric major depressive disorder. Am J Psychiatry. 2009;166:42-9.

27. Cheung AH, Emslie GJ, Mayes TL. Review of the efficacy and safety of antidepressants in youth depression. J Child Psychol Psychiatry. 2005;46:735-54.

28. Bachmann CJ, Aagaard L, Burcu M, Glaeske G, Kalverdijk LJ, Petersen I, et al. Trends and patterns of antidepressant use in children and adolescents from five western countries, 2005-2012. Eur Neuropsychopharmacol. 2016;26:411-9.

29. Emslie GJ, Heiligenstein JH, Wagner KD, Hoog SL, Ernest DE, Brown E, et al. Fluoxetine for acute treatment of depression in children and adolescents: a placebo-controlled, randomized clinical trial. J Am Acad Child Adolesc Psychiatry. 2002;41:1205-15.

30. Emslie GJ, Rush AJ, Weinberg WA, Kowatch RA, Hughes CW, Carmody $\mathrm{T}$, et al. A double-blind, randomized, placebo-controlled trial of fluoxetine in children and adolescents with depression. Arch Gen Psychiatry. 1997;54:1031-7.

31. March J, Silva S, Petrycki S, Curry J, Wells K, Fairbank J, et al. Fluoxetine, cognitive-behavioral therapy, and their combination for adolescents with depression: treatment for Adolescents With Depression Study (TADS) randomized controlled trial. JAMA. 2004;292:807-20.

32. Wagner KD, Robb AS, Findling RL, Jin J, Gutierrez MM, Heydorn WE. A randomized, placebo-controlled trial of citalopram for the treatment of major depression in children and adolescents. Am J Psychiatry. 2004;161:1079-83. 
33. Emslie GJ, Ventura D, Korotzer A, Tourkodimitris S. Escitalopram in the treatment of adolescent depression: a randomized placebo-controlled multisite trial. J Am Acad Child Adolesc Psychiatry. 2009;48:721-9.

34. Wagner KD, Ambrosini P, Rynn M, Wohlberg C, Yang R, Greenbaum MS, et al. Efficacy of sertraline in the treatment of children and adolescents with major depressive disorder: two randomized controlled trials. JAMA. 2003;290:1033-41.

35. Keller MB, Ryan ND, Strober M, Klein RG, Kutcher SP, Birmaher B, et al. Efficacy of paroxetine in the treatment of adolescent major depression: a randomized, controlled trial. J Am Acad Child Adolesc Psychiatry. 2001;40:762-72.

36. Emslie GJ, Findling RL, Yeung PP, Kunz NR, Li Y. Venlafaxine ER for the treatment of pediatric subjects with depression: results of two placebo-controlled trials. J Am Acad Child Adolesc Psychiatry. 2007;46:479-88.

37. Atkinson SD, Prakash A, Zhang Q, Pangallo BA, Bangs ME, Emslie GJ, et al. A double-blind efficacy and safety study of duloxetine flexible dosing in children and adolescents with major depressive disorder. J Child Adolesc Psychopharmacol. 2014;24:180-9.

38. Emslie GJ, Prakash A, Zhang Q, Pangallo BA, Bangs ME, March JS. A double-blind efficacy and safety study of duloxetine fixed doses in children and adolescents with major depressive disorder. J Child Adolesc Psychopharmacol. 2014;24:170-9.

39. Hazell P, O'Connell D, Heathcote D, Robertson J, Henry D. Efficacy of tricyclic drugs in treating child and adolescent depression: a meta-analysis. BMJ. 1995;310:897-901.

40. Hughes CW, Emslie GJ, Crismon ML, Posner K, Birmaher B, Ryan N, et al. Texas Children's Medication Algorithm Project: update from Texas Consensus Conference Panel on Medication Treatment of Childhood Major Depressive Disorder. J Am Acad Child Adolesc Psychiatry. 2007;46:667-86.

41. Weisz JR, McCarty CA, Valeri SM. Effects of psychotherapy for depression in children and adolescents: a meta-analysis. Psychol Bull. 2006;132:132-49.
42. Klein JB, Jacobs RH, Reinecke MA. Cognitive-behavioral therapy for adolescent depression: a meta-analytic investigation of changes in effect-size estimates. J Am Acad Child Adolesc Psychiatry. 2007;46:1403-13.

43. Mufson L, Weissman MM, Moreau D, Garfinkel R. Efficacy of interpersonal psychotherapy for depressed adolescents. Arch Gen Psychiatry. 1999;56:573-9.

44. Rossello J, Bernal G. The efficacy of cognitive-behavioral and interpersonal treatments for depression in Puerto Rican adolescents. J Consult Clin Psychol. 1999;67:734-45.

45. Mufson L, Dorta KP, Wickramaratne P, Nomura Y, Olfson M, Weissman MM. A randomized effectiveness trial of interpersonal psychotherapy for depressed adolescents. Arch Gen Psychiatry. 2004;61:577-84.

46. Dubicka B, Elvins R, Roberts C, Chick G, Wilkinson P, Goodyer IM. Combined treatment with cognitive-behavioural therapy in adolescent depression: meta-analysis. $\mathrm{Br} \mathrm{J}$ Psychiatry. 2010;197:433-40.

47. Goodyer I, Dubicka B, Wilkinson P, Kelvin R, Roberts C, Byford $\mathrm{S}$, et al. Selective serotonin reuptake inhibitors (SSRIs) and routine specialist care with and without cognitive behaviour therapy in adolescents with major depression: randomised controlled trial. BMJ. 2007;335:142.

48. Bridge JA, Iyengar S, Salary CB, Barbe RP, Birmaher B, Pincus $\mathrm{HA}$, et al. Clinical response and risk for reported suicidal ideation and suicide attempts in pediatric antidepressant treatment: a meta-analysis of randomized controlled trials. JAMA. 2007;297:1683-96.

49. Hammad TA, Laughren T, Racoosin J. Suicidality in pediatric patients treated with antidepressant drugs. Arch Gen Psychiatry. 2006;63:332-9. 